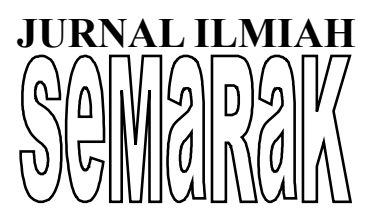

P-ISSN 2615-6849, E-ISSN 2622-3686

Jurnal Semarak,Vol. 2,No.3, Oktober 2019, Hal (31- 45)

(a) Prodi Manajemen Fakultas Ekonomi Universitas Pamulang

\title{
PENGARUH DISIPLIN KERJA DAN KESELAMATAN DAN KESEHATAN KERJA TERHADAP KINERJA KARYAWAN PADA PT. INKABIZ INDONESIA, TANGERANG SELATAN
}

\author{
Edy Krisyanto, SH, MM. \\ Staf Pengajar Fakultas Ekonomi Universitas Pamulang \\ email: dosen01108@unpam.ac.id atau krisyantoedy@yahoo.co.id
}

\begin{abstract}
ABSTRAK
Tujuan dari penelitian ini adalah untuk mengetahui pengaruh secara parsial antara disiplin kerja terhadap kinerja karyawan pada PT. Inkabiz Indonesia, untuk mengetahui pengaruh secara parsial antara keselamatan dan kesehatan kerja (K3) terhadap kinerja karyawan pada PT. Inkabiz Indonesia, untuk mengetahui pengaruh disiplin kerja dan keselamatan \& kesehatan kerja (K3) secara simultan (bersamasama) terhadap kinerja karyawan pada PT. Inkabiz Indonesia. Metode dalam penelitian adalah dengan menggunakan regresi linier berganda, dengan tahapan uji asumsi klasik (normalitas data, multikolinearitas dan heteroskedastisitas), koefisien determinasi, analisis koefisien regresi linier berganda dan uji signifikan ( $\mathrm{t}$ dan F). Data yang digunakan adalah data primer dengan cara membagikan kuesioner kepada responden yaitu karyawan pada PT. Inkabiz Indonesia yang berjumlah 50 karyawan. Hasil penelitian menunjukan bahwa bahwa secara parsial variabel disiplin kerja dan keselamatan \& kesehatan kerja (K3) berpengaruh terhadap kinerja karyawan. Secara simultan juga menunujukkan bahwa variabel disiplin kerja dan keselamatan \& kesehatan kerja (K3) berpengaruh terhadap kinerja karyawan. Berdasarkan hasil koefisien determinasi ditemukan bahwa variabel disiplin kerja dan keselamatan \& kesehatan kerja (K3) memiliki pengaruh sebesar 85,4\%, sedangkan sisanya 14,6\% dijelaskan dengan faktor atau variabel lain yang tidak diketahui dan tidak termasuk dalam analisis regresi ini, seperti gaji, motivasi kerja, lingkungan kerja dan lain-lain.
\end{abstract}

Kata kunci: disiplin kerja dan keselamatan \& kesehatan kerja (K3), kinerja karyawan.

\section{ABSTRACT}

The purpose of this research is to know the influence of partially between disciplines work on performance of employees at PT Inkabiz Indonesia, to know the influence of partially between safety and occupational health (K3) on performance employees at PT Inkabiz Indonesia, to know how the discipline of work and safety \& occupational health (K3) simultaneously (together) against the performance of employees at PT Inkabiz Indonesia. Methods in the research is to use multiple linear regression, with a classic assumption test phases (data normality, multicollinearity and heteroskedastisitas), the coefficient of determination coefficient of linear regression analysis, multiple and test significant ( $t$ and $F$ ). The data used are the primary data by way of distributing the questionnaire to respondents i.e. employees at PT. Inkabiz Indonesia that add up to 50 employees. The research results showed that that partially variable work discipline and safety \& occupational health (K3) effect on the performance of employees. Simultaneously also menunujukkan that the work discipline and safety variables \& occupational health (K3) effect on the performance of employees. Based on the results of the determination coefficient was found that work discipline and safety variables \& occupational health (K3) have influence of $85.4 \%$ $14.6 \%$, while the rest is explained by factors or other variables is unknown and not included in the regression analysis, such as salary, job motivation, work environment and more.

Keywords: work discipline, Occupationa, Health \& and Safety (K3), employee performance.

\section{PENDAhuluan}

\section{A. Lattar Belakang}

Perkembangan pesat sains dan

teknologi akan mewujudkan struktur baru, iaitu struktur global. Struktur ini telah menyebabkan semua negara di dunia, termasuk Indonesia, tidak dapat dielakkan terlibat dalam susunan global seragam, 


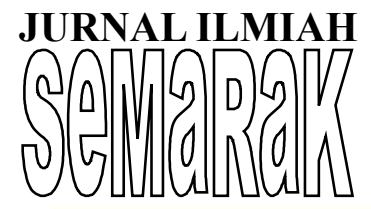

hubungan seragam dan hubungan, terutama dalam bidang sains dan teknologi. Aspek yang semakin pesat dalam Sains dan Teknologi, terutamanya komunikasi dan teknologi pengangkutan, telah menyebabkan isu-isu global menyebar lebih cepat dan mencapai pelbagai tetapan, baik politik, ekonomi sosio-kultural dan sektor pertahanan keselamatan. Dengan kata lain, globalisasi yang disokong oleh sains dan teknologi pesat telah menjadikan dunia telus tanpa mengetahui sempadan negara. Dengan perkembangan pesat teknologi, komuniti dunia, terutama rakyat Indonesia, sentiasa berubah seiring dengan perkembangan teknologi, dari masyarakat pertanian kepada masyarakat industri dan meneruskan teknologi teknologi pascateknologi. Mencapai matlamat dalam bidang politik, ekonomi, sosio-budaya dan pertahanan dan keselamatan cenderung semakin ditentukan oleh penguasaan teknologi dan maklumat, walaupun kualiti sumber daya manusia (HR) masih menjadi yang utama .

Sumber Manusia adalah salah satu faktor utama dalam pembaharuan ekonomi, iaitu bagaimana mencipta sumber daya manusia yang berkualiti dan berkemahiran dan sangat kompetitif dalam persaingan global yang kita telah diabaikan. Globalisasi yang pasti dihadapi oleh bangsa Indonesia menuntut kecekapan dan kekuasaan daya saing dalam dunia perniagaan. Dalam globalisasi yang melibatkan hubungan intraregional dan antarabangsa akan terdapat persaingan antara negara.

Tahap rendah sumber daya manusia Indonesia telah menyebabkan keadaan buruh mengalami beberapa masalah serius dan memerlukan peranan pemerintah yang berkesan untuk mengatasinya agar dapat mencapai daya saing yang tinggi Sumber Daya Manusia untuk menghadapi persaingan global, khususnya Komunitas Ekonomi Asia (MEA) .

Peningkatan sumber manusia dapat dilakukan dengan meningkatkan kepusan terhadap pekerja pekerja akan berusaha meningkatkan prestasinya jika dia berpuas hati dengan apa yang diperolehnya, apa yang dimaksudkan dengan kepuasan kerja pekerja adalah keadaan emosional yang menyenangkan atau tidak menyenangkan di mana para pekerja melihat pekerjaan mereka (Sunyoto, 2012:26) .

Kepuasan kerja merupakan tingkat rassa individu yang berpuas hati bahawa mereka diberi ganjaran sewajarnya dari bermacam-macam aspek situasi pekerjaan dari organisasi tempat mereka bekerja (Tangkilisan, 2011:164). Menurut (Griffin dan Ebert, 2011:269) kepuasan kerja adalah tingkat kegembiraan yang didapatkan dari orang karena melakukan pekerjaa, jika senang dengan pekerjaanya maka akan relatif puas. Karyawan yang puas mungkin memiliki semangat kerrja yanng tinggi. Semangat keerja mencerminkan seberapa jauh mereka memahami bahwa kebutuhan mereka 


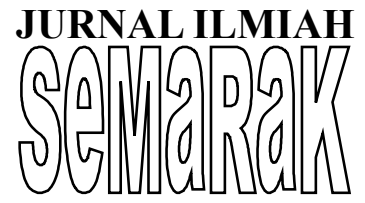

tercapai oleh pekerjaan mereka. Hal itu ditentukan oleh faktor-faktor seperti upah, tunjangan, rekan kerja dan peluang promosi .

Kepuasan akan berdampak pada disiplin kerja jika perusahaan mampu memberikan yang terbaik bagi karyawan, dengan kepuasan yang diberikan timbul rasa yang nyaman bagi karyawan, penelitian yang dilakukan oleh Parwita, Suparta dan Saroyeni (2009) menyatakan dalam penelitiannya bahwa kepuasan kerja akan mempengaruhi disiplin kerja jika perusahaan mampu memberikan upah, pengawasan, kenaikan jabatan dan hubungan kerja sesuai dengan harapan karyawan. Karyawan yang telah mendapatkan kepuasan, karyawan akan melaksanakan tugas sesuuai denngan pekerjaannya, melaksanakan pekerjaan tepat waktu dan akan menerima sanksi yang diberikan perusahaan jika melanggar aturan yang berlaku, karena karyawan secara psikologi sudah merasa nyaman dan tidak akan meninggalkan pekerjaan karena aturan yang bertujuan untuk kedisiplinan.

Faktor lainnya yang dapat mempengatuhi kinerja karyawan adalah kesselamatan daan keesehatan keerja (kK3), perlindungan atas keselamatan kerja karyawan ataupun buruh haruslan diutamakan oleh setiap perusahaan. Berbagai cara telah dilakukan untuk melindungi seluruh karyawan yang terlibat. Begitu pula dengan kesehatan kerja juga perlu dilakukan dan dijaga, sehinggan seluruh karyawan yang bekerja tetap sehat baik fisik maupun mentalnya. Kesehatan kerja yang perlu diperhatikan terutama selama bekerja dan berada di lingkungan kerj karyawan. Hal yang sesuai dengan bunyi undang-undang yang mengatakan bawah setiap pekerja mempunyai hak untuk memperoleh perlindungan atas (Kasmir, 2016:266) adalah 1) Keselamatan dan kesehatan keerja, 2) mooral daan kesopanan daan 3) perlakkuan yanng sessuai denngan haarkat daan marrtabah manuusia serta nilai-nilai agama.

Menuurut (Baangun, 2012:377) Keseelamatan Krrja adaalah perliindungan atas keamanan kerja yang dialami karyawan, baik fisik maupun mental dalam lingkungan pekerjaannya. Kesehatan Kerja (Bangun, 2012:377) adalah perlindungan atas keamanan dalam bekerja dalam hal perlindungan kesehatan.

Berdasarkan penjelasan yang diterangkan di atas, penulis berminat menjalankan penyelidikan dengan tajuk "Pengaruh Disiplin Kerja Dan Keselamatan dan Kesehatan Kerja Terhadap Kinerja Karyawan Pada PT. Inkabiz Indonesia, Tangerang Selatan”.

\section{B. Perumusan Masalah}

Berdasarkan batasan masalah diatas, makka massalah pennyelidikan dapat dirummuskan seperti berikut: 
1. Apakaah diisiplin kerjja berpngaruh secaara parrsial terrhadap kiinerja karyawan pada PT. Inkabiz Indonesia ?

2. Apakah Kesehatan dan Keselamatan Kerja berpengaruh parsial terhadap kinerja karyawan pada PT. Inkabiz Indonesia?

3. Apakah disiplin kerja dan kesehatan dan keselamatan kerja berpengaruh secara simultan terhadap kinerja karyawan pada PT. Inkabiz Indonesia ?

\section{Tujuan Penelitian}

Penelitian ini bertujuan untuk menguji dan menganalisis proses kegiatan yang dilakukan di PT. Inkabiz Indonesia, yaitu:

1. Untuk mengetahui pengaruh secara parsial antara variabel disiplin kerja terhadap kinerja karyawan pada PT. Inkabiz Indonesia.

2. Unntuk mengetahui pengaruh secara parsial antara variabel keesehatan daan keselamatan kerja terhadap kinerja karyawan pada PT. Inkabiz Indonesia.

3. Untuk mengetahui pengaruh secara simultan antara variabel disiplin kerja dan kesehatan dan keselamatan kerja terhadap kinerja karyawan pada PT. Inkabiz Indonesia.

\section{TINJAUAN PUSTAKA}

\section{A. Manajemen}

Manajemen berasal dari kosa kata bahasa Perancis kuno, yaitu menegement berarti seni melaksanakan dan mengatur. Pengertian manajemen dari para ahli memiliki beberapa perbedaan namun maksud dan tujuannya sama .

"Manajemen adalah ilmu dan seni mengatur, memanfaatkan sumber daya manusia dan sumber daya lainnya secara efektif dan efisien untuk mencapai suatu tujuan tertentu menurut SP. Hasibuan (2010:2)".

"Manajemen adalah proses untuk mencapai tujuan-tujuan organsiasi dengan melakukan kegiatan dari empat fungsi utama yang merencanakan (planning), proses mengorganisasian (organizing), memimpin (leading) dan proses mengendalikan (controlling). dengan demikian, manajemen adalah suatu kegiatan yang berkesinambungan.

Pengertian manajemen (Handoko, 2015:8) menjelaskan bahwa "manajemen adalah proses perencanaan, pengorganisasian, pengarahan dan pengawasan usaha-usaha para anggota organisasi dan penggunaan sumber dayasumber daya organisasi lainnya agar mencapai tujuan organisasi yang telah ditetapkan".

"Manajemen sebagai proses yang khas, yang terdiri atas tindakan-tindakan perencanaan, organisasian, mengerakkan, dan pengawasan yang dilakukan untuk menentukan serta mencapai sasaransasaran yang telah ditetapkan melalui pemanfaatan sumber daya manusia serta sumber-sumber lainnya untuk mencapai tujuan tertentu (Danim, 2010:18)”. 


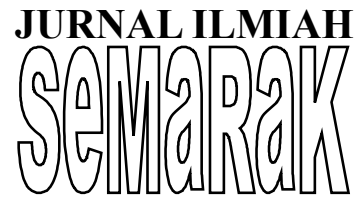

Berdasarkan pendapat diatas dapat diambil makna bawah manajemen mengandung arti optimalisasi sumbersumber daya atau pengelolaan dan pengendalian. Sumber-sumber daya yang optimal, dikelola dan dikendalikan tersebut meliputi sumber daya manusia dan sumber pendukung lainnya. Proses tersebut mencakup lngkah-langkah perencanaan, organisasian, pelaksanakan dan pengendalian .

\section{B. Manaajemen Summber Dayya Mannusia}

Manajemen Sumber Daya Manusia adalah proses pengelolaan manusia, melaluui perrencanaan, rekrrutmen, seeleksi, peelatihan, penggembangan, pemberiian kompensasi, karier, keselamatan dan kesehatan serta menjaga hubungan industrial sampai pemutusan hubungan kerja guna mencapai tujuan perusahaan dan peningkatan kesejahteraan stakeholder. Pengertian manajemen sumber daya manusia dari beberapa ahli MSDM: Noe menyebutkan Human Resources Management refers to Policies, practices and systems that influenza employees' behavior, attitudes, and performance (manajemen sumber daya manusia merupakan bagaiman mempengaruhi perilaku, sikap dan kinerja melalui kebijakan dan sistem yang dimiliki oleh perusahaan. Menurut Dessler Human Resources Management is the process of acquiring, training, appraising and compensating employees, and attending their labor relations, health and safety, and fairness concern (manajemen sumber daya manusia merupakan proses menangani karyawan pelatihan penilaian, kompensasi, hubungan kerja kesehatan dan keamanan secara adil terhadap fungsifungsi MSDM (Kasmir, 2015:6).

Mengelola sumber manusia mesti dilakukan dengan betul mengikut prinsipprinsip manusia atau alam semula jadi. Jika pada zaman dahulu manusia atau pekerja dianggap mesin yang dapat dilakukan dengan semena-mena demi mencapai tujuan perusahaan. Manusia dianggap sebagai budak yang dapat diperintah semaunya. Namun saat ini sesuai dengan perkembangannya, manusia semakin diperhatikan bahkan sekarang sudah berubah menjadi asset yang paling penting untuk diperhatikan (Kasmir, 2016:5) .

Sutrisno (2016:3) mengatakan bahwa sumber daya manusia merupakan satusatunya sumber daya yang memiliki akal perasaan, keinginan, keterampilan, pengetahuan, dorongan, daya dan karya (rasio, rasa dan karsa). Semua potensi sumber daya manusia tersebut beerpengaruh teerhadap uppaya organsasi dalam mencapai suatu tujuan.

Menurut Bangun (2012:5) pengertian manajemen summber dya maanusia adlah suatu kegiatan yang meliputi perencanaan, organisasi, penyediaan kakitangan, penggerak dan penyeliaan fungsi operasi untuk mencapai tujuan perusahaan. 


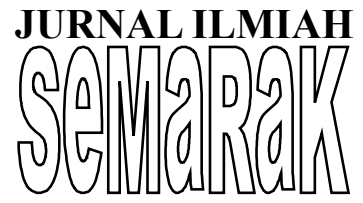

Berdasarkan pengertian di atas maka dapat disimpulkan pengertian Manajemen Sumber Daya Manusia adalah segalah kegiatan dengan menggerakan sumber dayya maanusia yaang ada untuk mencapai tujuan perusahaan.

\section{Disiplin Kerja $\left(\mathbf{X}_{1}\right)$}

Disiplin merupakan prosedur yang mengoreksi atau menghukum bawahan karena melanggar peraturan atau prosedur (Rosidah, 2009:290). Disiplin merupakan bentuk pengendalian diri pegawai dan pelaksanaan yang teratur dan menunjukan tingkat kesungguhan tim kerja di dalam sebuah organisasi (Rosidah, 2009:290).

Mennurut Undaang-Unndang Noo. 35 Tahuun 2012 yang diimaksud deengan disiplin kerja pegawai adalah kesanggupan pegawai untuk menaati kwajiban dan menghindari larangan yang ditentukan dalam peraturan perundangundangan dan / atau peraturan kedinasan yang apabila tidak ditaati atau dilarang dijatuhi hukuman disiplin.

Daalam disiplin adanya hukuman disiplin, yang dimaksud hukuman disiplin mennurut Unndang-Unddang $\mathrm{N}$ o. 35 Tah un 2012 hukuman yang dijatuhkan kepada pegawai karena melanggar peraturan disiplin pegawai.

Tindakan disiplin sebagaimana diterangkan oleh simamora dalam Rosidah (2009:291) menuntut suatu hukuman terhadap pegawai yang gagal memenuhi standar-standar yang ditentukan. Tindakan disiplin yang dilaksanakan dengan tidak betul adalah merosakkan pekerja dan organisasi. Oleh itu, tindakan disiplin haruslah tidak diterapkan secara sembarangan, melainkan memerlukan pertimbangan yang bijak (Rosidah, 2009:291).

"Disiplin kerja merupakan suatu alat yang digunakan para manajer untuk berkomunikasi dengan karyawan agar mereka bersedia untuk mengubah suatu prilaku serta sebagai suatu upaya untuk meningkatkan kesadaran dan kesediaan seseorang menaati semua peraturan perusahaan dan norma-norma sosial yang berlaku (Rivai dan Sagala, 2009:824)”.

Menurut Dessler (2009:194) “disiplin kerja merupakan suatu aturan yang dibuat perusahaan atau organisasi yang bertujuan untuk mendorong karyawan berprilaku hati-hati dalam bekerja sehingga dapat menyelesaikan suatu permasalahan".

Berdasaarkan penngertian disiiplin kerrja yang diuungkapkan paara ahlli di attas, maka dapat dibuat suatu kesimpulan yang dimaksud dengan disiplin kerja adalah suatu bentuk pengendalian diri pegawai dan pelaksanaan yang teratur dan menunjukan tingkat kesungguhan tim kerja di dalam sebuah organisasi dalam bentuk peraturan dan undang-undang yang dibuat perusahaan dengan tujuan agar karyawan berhati-hati dalam bekerja sehingga menyelesaikan suatu permasalahan. 


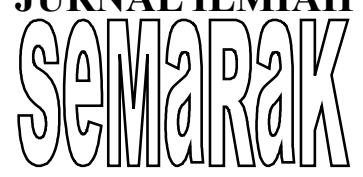

P-ISSN 2615-6849, E-ISSN 2622-3686

Jurnal Semarak,Vol. 2,No.3, Oktober 2019, Hal (31- 45)

(a) Prodi Manajemen Fakultas Ekonomi Universitas Pamulang

\section{Kesehatan dan Keselamatan Kerja $\left(X_{2}\right)$}

Menurut Kasmir (2016:266)

Keselamatan kerja adalah merupakan aktivitas perlindungan karyawan secara menyeluruh, perusahaan berusaha untuk menjaga jagan sampai karyawan mendapat suatu kecelakaan pada saat menjalankan aktivitasnya. Kesehatan kerja (Kasmir, 2016:266) adalah upaya menjaga karyawan tetap sehat selama berkerja, jangan sampai kondisi lingkungan kerja akan membuat karyawan tidak sehat atau sakit.

Kesehatan kerja (Riani, 2013:140) adalah usaha penyediaan fasilitas kesehatan di tempat kerja yang diperuntukan untuk karyawan. Keselamatan kerja (Riani, 2013:140) adalah usaha untuk memberikan rasa aman dan nyaman kepada karyawan dalam melaksanakan aktivitasnya.

Perlindungan atas keselamatan kerja karyawan ataupun buruh haruslan diutamakan oleh setiap perusahaan. Berbagai cara telah dilakukan untuk melindungi seluruh karyawan yang terlibat. Begitu pula dengan kesehatan kerja juga perlu dilakukan dan dijaga, sehinggan seluruh karyawan yang bekerja tetap sehat baik fisik maupun mentalnya. Kesehatan kerja yang perlu diperhatikan terutama selama bekerja dan berada di lingkungan kerj karyawan.

Hal yang sesuai dengan bunyi undang-undang yang mengatakan bawah setiap pekerja mempunyai hak untuk memperoleh perlindungan atas (Kasmir, 2016:266):

1. Keselamatan dan keseehatan keerja

2. Morral daan kessusilaan

3. Perlakkuan yanng sessuai deengan harrkat dan martabah manusia serta nilai-nilai agama.

Untuk melindungi keselamatan karyawan guna mewujudkan produktivitas kerja yaang opptimal disselenggarakan uppaya keeselamatan dann kessehatan keerja. Perlindungan dilaksanakan sesuai dengan perraturan perunndang-unddangan yaang berrlaku .

Konsep kesellamatan dann kesehhatan keerja bukan sesuatu yang baru bagi banyak perusahaan dan menjadi tanggung jawab perusahaan untuk melindungi perusahaan. Seseorang sehat, tidak masalah tentang kondisi fisik atau mental dan emosional, akan dapat melaksanakan aktivitasnya secara normal. Keselamatan dan kesehatan kerja sesuatu yang diinginkan oleh setiap angora organisasi. Sama dengan itu, pemberi kerja berusaha untuk memberikan kesejahteraan kepada para karyawannya. Perusahaan besar umumnya memiliki bagian yang menangani bidang keselamatan dan kesehatan kerja, sementara di perusahaan kecil ditangani langsung bagian sumber daya manusia atau manajer. 


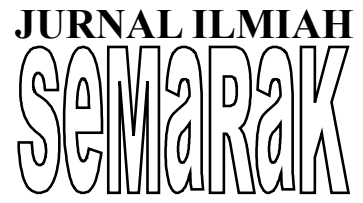

Menurut

(Bangun,

2012:377)

Keselammatan Keerja merupakan perlinndungan attas keammanan kerjja yanng dialaami karryawan, baaik fissik mauupun menntal dalam lingkungan pekerjaannya. Kesehatan Kerja (Bangun, 2012:377) adalah perlindungan atas keamanan dalam bekerja dalam hal perlindungan kesehatan.

Berdasarkan pendapat para ahli dalam disimpulkan bahwa pengertian Kesellamatan dan Kessehatan Kerrja adalah setiap usaha perusahaan untuk memberikan perlindungan kepada karyawannya dalam menjalanan aktivitasnya dan penyedian tempat sebagai fasilitas kesehatan untuk membuat rasa nyaman kepada karyawan dalam bekerja.

\section{E. Kinerja Karyawan (Y)}

Kinerja merupakan tingkat produktivitas seorang karyawan, relatif kepada rakan sekerja, mengenai beberapa keputusan dan tingkah laku yang berkaitan dengan tugas itu. Kinerja dipengaruhi oleh variabel yang terkait dengan pekerjaan meliputi role-stress dan konflik kerja / non-kerja (Riani, 2013:61).

Pengertian lain mengenai kinerja diungkapkan oleh Riani (2013:61) menyatakan bahwa kinerja adalah hasil dicapai oleh seseorang mengikut saiz yang berkenaan dengan kerja yang dimaksudkan.

Prestasi seseorang adalah kombinasi keupayaan, usaha dan peluang yang dapat dinilai dari hasil karyanya (Rosidah, 2009: 276). Prestasi individu dipengaruhi oleh usaha (usaha), kemampuan (kemampuan) dan situasi alam sekitar (Subhki dan Jauhar, 2013: 41).

Russsell dalam Rosidah (2009: 276) menyatakan bahawa prestasi adalah rekod keluar yang dihasilkan daripada fungsi atau aktiviti pekerja tertentu yang dijalankan dalam tempoh masa. Prestasi kedudukan secara keseluruhan adalah sama dengan bilangan (purata) prestasi fungsi pekerja atau aktiviti yang yang dijalankan (Rosidah, 2009: 276) .

Berdasarkan pemahaman prestasi kerja pekerja, dapat disimpulkan bahwa apa yang dimaksudkan dengan kinerja karyawan adalah tingkat produktivitas karyawan, dibandingkan dengan rekan kerja mereka, mengenai beberapa hasil dan tingkah laku yang berkaitan dengan tugas sesuai dengan langkah-langkah yang berlaku untuk pekerjaan yang dimaksudkan .

\section{F. Hipotesis Penelitian}

Hipotesis yang diuji dalam penelitian ini berkaitan dengan ada atau tidaknya pengaruh yaang signifikan dari seperangkat pembolehubah bebas kepada pemboleh ubah bergantung. Adapan hipotesis yang diuji yakni sebagai berikut:

1. $\mathrm{H}_{\mathrm{o}}$ : variiabel disiplin kerja tidak berpengaruh secara parsial terhadap kinerja karyawan. 


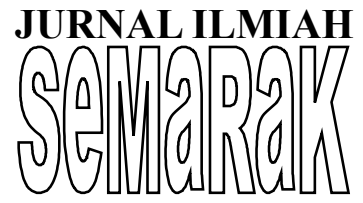

$\mathrm{H}_{\mathrm{a}}$ : variabel disiplin kerja berpengaruh secara parsial terhadap kinerja karyawan.

2. $H_{0}$ : variiabel kessehatan ddan keselamatan kerja tidak berpengaruh secara parsial terhadap kiinerja karyawan.

$\mathrm{H}_{\mathrm{a}}$ : variabel kesehatan dan keselamatan kerja berpengaruh secara parsial terhadap kinnerja karyawan.

3. $H_{o}$ : variabel disiplin kerja dan kesehatan dan keselamatan kerja tidak berpengaruh secara simultan terhadap kineja karyawan.

$\mathrm{H}_{\mathrm{a}}$ : variabel disiplin kerja dan kesehatan daan keselamatan kerja berpengaruh secara simultan terhadap kineja karyawan.

\section{METODE PENELITIAN}

Penelitian dilakukan pada PT. Inkabiz Indonesia, Tangerang Selatan. Metode yang digunakan dalam penelitian ini adalah metode kuantitatif. Dengan menggunakan metode analisis regresi linier berganda. Populasi sasaran dalaam penelitian ini adalah karyawan yang bekerja di PT. Inkabiz Indonesia sebanyak 133 orang yang bekerja di PT. Inkabiz Indonesia. Sampel yang penulis masukkan dalam penelitian adalah sebanyak 100 orang karyawan yang didapat dari rumus slovin yang dapat di tunjukkan oleh perhitungan sebagai berikut:

$\mathrm{n}=\frac{133}{1+133\left(0,05^{2}\right)}$

$\mathrm{n}=\frac{133}{1,3325}=99,8 / 100$ Karyawan

Pengumpulan data dilakukan dengan cara dokumentasi, wawancara dan kuesioner.

\section{HASIL DANN PEMBAHASAN}

\section{A. Gambaran Objek Penelitian}

PT. Inkabiz Indonesia merupakan perusahaan yang bergerak dibidang garmen dengan memiliki kualitas yang cukup baik. PT. Inkabiz Indonesia pertama kali didirikan oleh Bapak Soedarsono pada tahun 2007 dengan dasar akte Notaris Mutiara Siswono, SH dengan no 38 tanggal 29 mei 2007.

Proses pekerjaan pada PT. Inkabiz Indonesia terdiri dari cutting process, bagiian inni merrupakan baggian peertama dalam prooses prooduksi, PT. Innkabiz Inndonesia mempunyai tenaga ahli dalam memotong bahan tekstil termasuk: kain dan interlining untuk membuat komponen yang siap untuk dikerjakan pada proses penjahitan. Perlakuan dan teknik pemotongan setiap kain bervariasi tergantung dari karakteristik kain. Maka dari itu pada bagian ini diperlakukan keterampilan operator yang terlatih dan berpengalaman. 


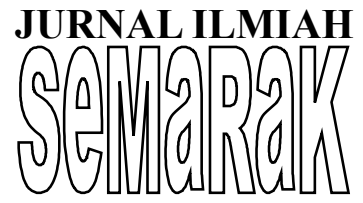

Pada proses kedua adalah sewwing

Proses jahit menggabungkan panel pakaian dengan menjahit dengan mesin di ruang jahit. Dengan tenaga kerja profesional. Setiap mesin dikendalikan oleh setiap operator dan pengendali jahit hanya dalam satu atau dua jenis proses pakaian. Di dalam barisan ini terdiri daripada pengendali mesin jahit, pembantu untuk membantu membekalkan kepingan pakaian, benang dan lain-lain, kualiti dam dan satu penyelia.

Proses selanjutnya adalah finishing, pada proses ini sudah termasuk dalam proses memeriksa garmen, memeriksa ukuran, setrika/gosokan dan bercak. Setelah garmen dijahit, semua garmen yang dicek oleh quality checker untuk memastikan bahwa garmen dibuat sesuai stanndar kauulitas buyer. Seetiap gaarmen kemuudian diseetrika unntuk menghilangkan kusut dengan cara ditekan proses penyetrikaannnya.

Proses terakhir adalah delivery, setelah packaging dilakukan secara secara individu atau gabungan untuk kemudahan atau keselamatan barangan. PT. Inkabiz Indonesia memiliki armada sendiri yang memadai untuk melakukan proses perkapalan. Dengan keselamatan dan ketepatan masa barang-barang tiba di destinasi.

\section{B. Analisis dan Pembahasan}

\section{Hasil Ujii Valiiditas}

Kesahan adalah ukuran yang menunjukkan sejauh mana alat ukur dapat mengukur apa yang diukur. Menurut Ghozali (2013:52) ujian kesahihan digunakan untuk mengukur kesahihan atau kesahihan kuesioner. Berikut ialah keputusan ujian kesahihan:

Tabel 1

\section{Hasil Uji Validitas}

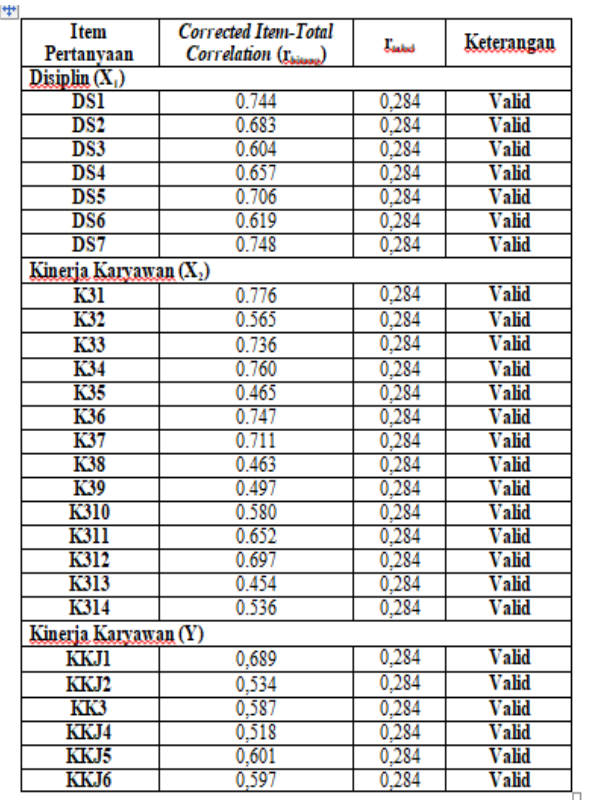

Dari hasil uji validitas tersebut, diperoleh data yang menyatakan bahwa dari item pertanyaan yang diberikan kepada 50 responden ditemukan nilai Corrected Item-Total Correlation ( $\left.\mathrm{r}_{\text {tabel }}\right)$ lebih besar dari nilai $0,284\left(\mathrm{r}_{\text {tabel }}\right)$ yang berarti valid maka dapat dilanjutkan ke penelitian berikutnya.

\section{Hasil Uji Reliabilitas}

Ujian kebolehpercayaan ini digunakan untuk menguji konsistensi data dalam tempoh masa tertentu, iaitu untuk menentukan sejauh mana pengukuran yang digunakan boleh dipercaya atau 
dipercayai. Pembolehubah alpha cronbach dikatakan mempunyai nilai yang lebih besar daripada 0.70 yang bermaksud bahawa instrumen tersebut boleh digunakan sebagai pengumpul data yang boleh dipercayai, yang merupakan hasil pekali pengukuran relatif jika pengukuran berulang dibuat. Ujian kebolehpercayaan ini bertujuan untuk melihat konsistensi (Ghozali, 2013: 48). Berikut ialah keputusan ujian kebolehpercayaan:

Tabel 2 Hasil Uji Reliabilitas

\begin{tabular}{|l|c|c|c|}
\hline \multicolumn{1}{|c|}{ Item Pertanyaan } & $\begin{array}{c}\text { Cronbach's } \\
\text { Alphla }\end{array}$ & $\begin{array}{c}\text { NOf } \\
\text { Item! }\end{array}$ & Keterangan \\
\hline DisiplinKerja $\left(\mathrm{X}_{1}\right)$ & 0,888 & 7 & Reliabel \\
\hline KeselamtandanKesehatanKeria/K3 $\left(\mathrm{X}_{2}\right)$ & 0,909 & 14 & Reliabel \\
\hline Kinerjakarvaman(Y) & 0,822 & 6 & Reliabel \\
\hline
\end{tabular}

Berdasarkan jadual di atas, dapat dilihat bahwa pembolehubah yang terdiri dari disiplin kerja, keselamatan dan kesihatan / K3 dan prestasi pekerja mempunyai data yang dapat diandalkan, ini dapat dilihat dari nilai alpha cronbach lebih besar dari 0.70. Ini membuktikan bahawa kajian ini dapat diteruskan .

\section{Hasil Uji Asumsi Klasik}

\section{a. Hasil Uji Normalitas}

Ujian normalisasi bertujuan sama ada dalam model regresi pembolehubah bergantung (bebas) dan pembolehubah bebas (bebas) mempunyai sumbangan atau tidak (Ghozali, 2013: 147). Berikut adalah hasil ujian normal:

1) Analisis Grafik

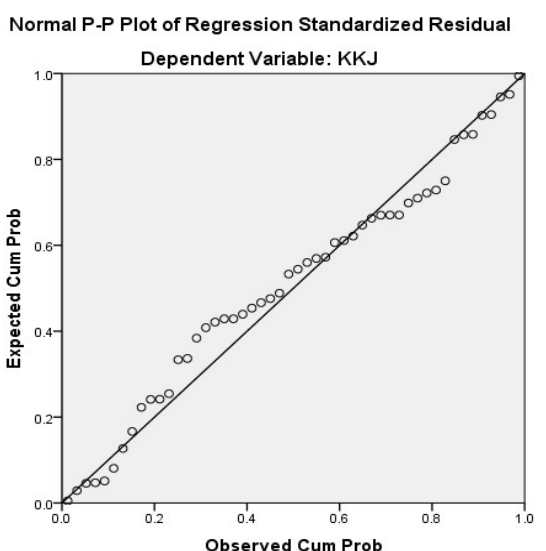

Ga mbar 1

Has il U ji Nor malitas Da ta (S ecara G rafik)

Pada grafik normal plot menunjukkan titik tersebar di sekitar garis pepenjuru, dan penyebaran mengikuti arah garis pepenjuru. Kedua-dua graf ini menunjukkan bahawa model regresi adalah mungkin kerana andaian normal (Ghozali 2013: 163) .

2) Analisis Statistik

Selain dengan analisis grafik maka perlu dianjurkan dengan uji statistik, agar mencapai ketepatan yang lebih baik. Ujian normalisasi statistik boleh dilihat berdasarkan ujian smyrnov kolmogorof, adapun pengujianya adalah sebagai berikut:

\section{T abel 3}

\section{$H$ asil $U$ ji Normalitas Data}

(Secara Statistik)

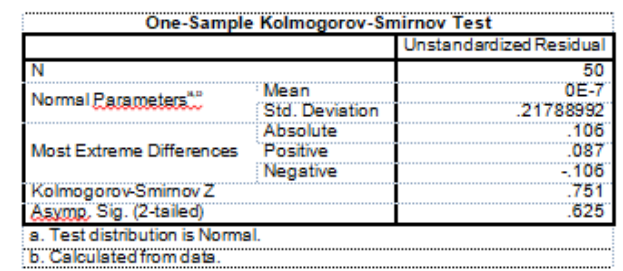




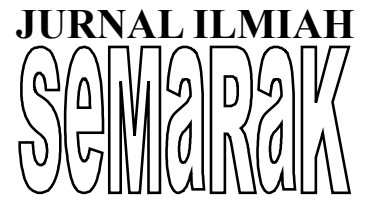

Berdasarkan

P-ISSN 2615-6849, E-ISSN 2622-3686

Jurnal Semarak,Vol. 2,No.3, Oktober 2019, Hal (31- 45)

@ Prodi Manajemen Fakultas Ekonomi Universitas Pamulang

ujian Kolmogorov-

Smirnov, dapat dilihat nilai sisa yang tidak mempunyai nilai Asymp. Sig. $>0.05$, ini bermakna data diedarkan secara normal.

b. Hasil U ji Multikoolinearitas

Tabel 4

Hasil U ji Multikoolinearitas

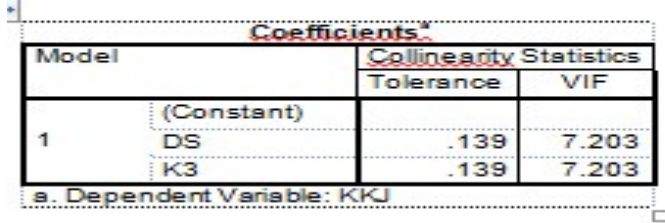

Berdasarkan jadual di atas, dapat dilihat bahawa nilai Toleransi tidak kurang daripada 0.1 dan Nilai Faktor Inflasi Variasi (VIF) tidak lebih dari 10, analisis ini dapat disimpulkan bahawa model regresi berganda linear bebas dari anggapan klasik, sehingga pembolehubah dapat digunakan dalam penyelidikan .

\section{c. H asil U ji Heteroskesdastisitas}

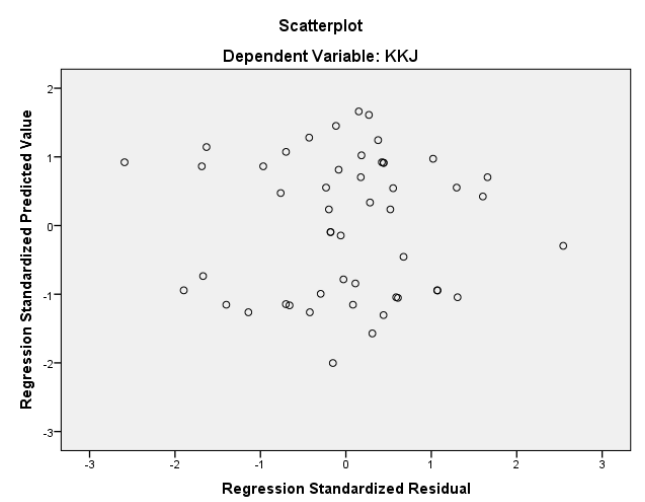

Gambar 2

\section{Hasil Uji Heteroskedastisitas}

Dari graf Scatterplot dalam gambar di atas, dapat dilihat bahawa titik-titik itu tersebar secara rawak, dan menyebarkan kedua-duanya di atas dan di bawah sifar pada paksi Y. Dapat disimpulkan bahawa tidak ada heteroscedasticity dalam model regresi. (Ghozali 2013: 139).

\section{Haasil Ujii Hiipotesis Peneelitian}

\section{a. Has il U ji t (H asil U ji Se cara Parsi al)}

Ujian separa hipotesis ini bertujuan untuk menentukan sama ada terdapat pengaruh separa pembolehubah bebas pada pemboleh ubah bergantung. Hasil hipotesis dalam ujian ini adalah seperti berikut:

Ta bel 5

Ha sil U ji t (Par sial)

\begin{tabular}{|c|c|c|c|c|c|c|}
\hline \multirow{3}{*}{ Mod } & \multicolumn{6}{|c|}{ Coefficients } \\
\hline & & \multicolumn{2}{|c|}{$\begin{array}{l}\text { Unstandardized } \\
\text { Coefficients }\end{array}$} & \multirow{2}{*}{\begin{tabular}{|c|}
$\begin{array}{c}\text { Standardized } \\
\text { Coefficients }\end{array}$ \\
Bets \\
\end{tabular}} & \multirow[t]{2}{*}{ t } & \multirow[t]{2}{*}{ Sig. } \\
\hline & & $\mathrm{B}$ & Std. Error & & & \\
\hline \multirow{3}{*}{1} & (Constant) & .095 & .253 & & .376 & .709 \\
\hline & DS & .601 & .150 & .599 & 4.007 & .000 \\
\hline & K3 & .378 & .166 & .341 & 2.283 & .027 \\
\hline
\end{tabular}

Berdasarkan data di atas, dapat dilihat bahawa sebahagian daripada pembolehubah disiplin kerja mempunyai kesan yang signifikan terhadap prestasi pekerja, dalam pembolehubah K3 juga mempunyai pengaruh yang signifikan terhadap prestasi pekerja sebahagiannya.

\section{b. Hasil Uji Simultan F}

Tabel 6 Hasil Uji t (Parsial)

\begin{tabular}{|l|r|r|r|r|r|r|}
\hline Model & & Sum of Squgres & df & Megn Square & F & Sig. \\
\hline \multirow{4}{*}{1} & Regression & 13.631 & 2 & 6.816 & 137.700 & $.000^{\circ}$ \\
& Residual & 2.326 & 47 & .049 & & \\
& Total & 15.958 & 49 & & & \\
\hline
\end{tabular}

Dalam jadual analisis varians (Anova), keputusan ujian $\mathrm{F}$ dipaparkan yang dapat digunakan untuk meramalkan sumbangan aspek disiplin kerja dan pembolehubah keselamatan dan kesihatan (K3) kepada pemboleh ubah prestasi 
pekerja. Daripada pengiraan, nilai F yang dikira adalah 137,700. Dengan tahap penting $5 \%$ dan df1 $=2$ dan df $2==47$, nilai Ftable $=3.09$ diperolehi. Oleh kerana nilai Fcount $(137,700)>$ nilai jadual $F$ (3.09), dapat disimpulkan bahawa dua pembolehubah bebas iaitu disiplin kerja dan keselamatan dan kesihatan pekerjaan (K3) menyumbang secara signifikan kepada pemboleh ubah prestasi pekerja. Sehingga model regresi yang diperoleh sesuai untuk digunakan untuk meramalkan. Kemudian dapat disimpulkan bahwa Ho ditolak dan $\mathrm{Ha}$ diterima.

\section{Hasil Koefisien Persamaan Regresi}

\section{Linier Berganda}

Tabel 7

Hasil Uji t (Parsial)

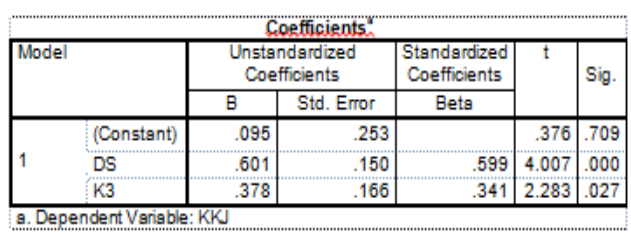

Berdasarkan hasil yang diperoleh dari pekali regresi di atas, persamaan regresi boleh dibuat seperti berikut:

$$
\mathrm{Y}=0.095+0.601 \mathrm{X1}+\mathbf{0 . 3 7 8} \mathrm{X2}
$$

Dalam persamaan regresi di atas menunjukkan nilai tetap 0.095 . Ini menyatakan bahawa jika disiplin kerja dan keselamatan dan kesihatan (K3) pembolehubah dianggap malar atau bernilai 0 (sifar), maka prestasi pekerja akan meningkat sebanyak 0.095 .

Pekali regresi pada pemboleh ubah disiplin kerja adalah 0.601, ini bermakna jika pembolehubah disiplin kerja meningkat satu unit maka pemboleh ubah prestasi pekerja akan meningkat sebanyak 0.601. Perhatikan bahawa pembolehubah lain dianggap malar.

Pekali regresi pada pemboleh ubah keselamatan dan kesihatan pekerjaan (K3) adalah 0.378 , ini bermakna jika pemboleh ubah keselamatan dan kesihatan pekerjaan (K3) meningkat satu unit maka prestasi pekerja berubah-ubah akan meningkat sebanyak 0.378. Perhatikan bahawa pembolehubah lain dianggap malar.

\section{Hasil Koefisien Determinasi $\left(R^{2}\right)$}

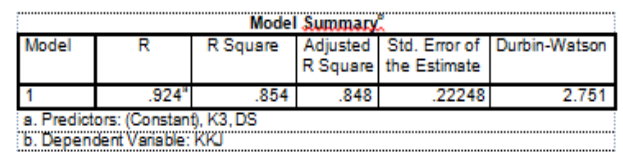

Koefisien penentuan (R2) bertujuan untuk mengetahui sejauh mana kebolehan pembolehubah bebas (disiplin kerja dan keselamatan dan kesihatan pekerjaan (K3)) dapat menjelaskan pemboleh ubah bergantung (prestasi pekerja). Berdasarkan jadual di atas, diketahui bahawa nilai $\mathrm{R}$ square adalah $0.854 \quad(85.4 \%) \quad$ Ini menunjukkan bahawa dengan menggunakan model regresi yang diperoleh di mana pembolehubah bebas iaitu disiplin kerja dan keselamatan dan kesihatan pekerjaan (K3) mempunyai pengaruh terhadap pemboleh ubah prestasi pekerja sebanyak $85,4 \%$.

\section{KESIMPULAN DAN SARAN}

\section{A. Kesimpulan}

Berdasarkan hasil penyelidikan dan analisis yang dijelaskan dalam bab 


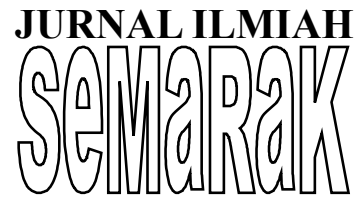

sebelumnya oleh penulis tentang pengaruh disiplin kerja dan kesehatan dan keselamatan kerja terhadap kinerja karyawan di PT. Inkabiz Indonesia, Tangerang Selatan, dapat disimpulkan oleh para peneliti, yaitu:

1. Berdasarkan keputusan ujian $t$ (sebahagian) didapati disiplin kerja mempengaruhi prestasi pekerja.

2. Berdasarkan hasil uji t (parsial) ditemukan bahwa keselamatan dan kesehatan kerja (K3) berpengaruh terhadap kinerja karyawan.

3. Berdasarkan keputusan ujian F (serentak) didapati disiplin kerja dan keselamatan dan kesihatan pekerjaan mempengaruhi prestasi pekerja

B. Saran

Penelitian ini memberikan sumbangsih saran bagi kemajuan PT. Inkabiz Indonesia, Tangerang Selatan terutama dibidang sumber daya manusia mengenai disiplin kerja dan kesehatan dan keselamatan kerja dengan saran-saran dalam peningkatan kinerja karyawan. Saran masukan dari peneliti untuk PT. Inkabiz Indonesia, Tangerang Selatan adalah:

1. Dalam rangka meningkatkan disiplin oleh pekerja kemudian PT. Inkabiz Indonesia mesti dapat memperbaiki strateginya dengan lebih tepat dalam meningkatkan disiplin kerja dengan memberikan sekatan kepada pekerja yang tidak berdisiplin dan menetapkan masa yang lebih ketat untuk pekerja.

2. Dalam rangka meningkatkan keselamatan dan kesehatan kerja (K3) oleh karyawan maka PT. Inkabiz Indonesia, Tangerang Selatan harus dapat meningkatkan K3 dengan melengkapi alat pelindung diri yang tepat, mengawasi kelengkapan kerja yang masih layak dan menambah alat yang lengkap sesuai dengan standar.

\section{DAFTAR PUSTAKA}

Ardana, I Komang, Mujiati, Ni Wayan \& Utama, I Wayan Mudhiartha, "Sumber Daya Manusia", Graha Ilmu, Yogyakarta, 2012 .

Bangun, Wilson, "Manajemen Sumber Daya Manusa", Jakarta, Erlangga, 2012 .

Dessler, Gary, "Manajaemen Sumber daya Manusia”, Indeks, Jakarta, 2011 .

Ghozali, Imam, "Aplikasi Analisis Multivariat Dengan Program SPSS 21", Badan Penerbit Universitas Dipenogoro, Semarang, 2013 .

Handoko, T. H, “Manajemen”, BPFE, Yogyakarta, 2015 .

Hariandja, Marihot Tua Efendi, "Manajemen Sumber Daya Manusia", Grasindo, Jakarta, 2010 .

Hasibuan, Melayu, "Manajemen Sumber Daya Manusia”, PT. Bumi Aksara, Jakarta, 2010 .

http://hdr.undp.org/en/composite/HDI, diakses pada tanggal 6 Agustus 2018 . 
http://www.tribun-maluku.com, diakses pada tanggal 6 Agustus 2018 .

\section{Istijanto, "Aplikasi Praktis Riset Pemasaran: Cara Praktis Meneliti Konsumen dan Pesaing”, PT Gramedia Pustaka Utama, Jakarta, 2010 .}

Kasmir, "Manajemen Sumber Daya Manusia (Teori dan Praktik)", PT. Raja Grafindo Persada, Jakarta, 2016 .

Putra, Gede Prawira Utama dan Made Subudi, "Pengaruh Disiplin Kerja, Gaya Kepemimpinan, Dan Motivasi Kerja Terhadap Kinerja Karyawan Pada Hotel Matahari Terbit Bali Tanjung Benoa-Nusa Dua", Jurnal Manajemen Bali, 2013.

Riani, Asri Laksmi, "Manajemen Sumber Daya Manusia, Graha Ilmu, Yogyakarta, 2013.

Rivai, Veithzal dan Sagala Jauvani Ela, "Manajemen Sumber Daya Manusia Untuk Perusahaan”, Edisi Kedua, Rajawali Pers, Jakarta, 2011 .

Robbins, Stephen $\mathrm{P}$ dan Coulter, "Perilaku Organisasi", Edisi kesepuluh, PT. Indeks Kelompok Gramedia, Jakarta, 2010

Rosidah, Ambar Teguh Sulistiyani, "Manajemen Sumber Daya Manusia", Graha Ilmu, Yogyakarta, 2009 .

Sugiyono, "Metode Penelitian Pendidikan Pendekatan Kuantitatif, Kualitatif dan $R \& D ”, \quad$ Alfabeta, Bandung, 2016 .
Sunyoto, Danang, "Sumber Daya Manusia (Praktik Penelitian)”, Center For Academic Publishing Service, Yogyakarta, 2012 .

Sutrisno Edi, "Manajemen Sumber Daya Manusia", Kencana, Jakarta, 2016 .

Swastha, Bashu, Ibnu Sukotjo, "Pengantar Bisnis", Liberti, Yogyakarta, 2010 .

Pasaribu, V. L. D., \& Krisnaldy, K. (2018). ANALISIS KEPUASAN JAMA'AH PADA KINERJA DEWAN KEMAKMURAN MASJID AL-HIDAYAH PERIODE TAHUN 2017. KREATIF: Jurnal Ilmiah Prodi Manajemen Universitas Pamulang, 6(4), 41-51.

Umar, Husein, "Riset Strategi Pemasaran”, Gramedia Pustaka Utama, Jakarta, 2010 .

Wibowo, "Manajemen Kinerja", Edisi Ke Tiga, Rajawali Pers, Jakarta, 2010 .

Wijaya, Andree, "Pengaruh Kemampuan Dan Motivasi Terhadap Kinerja Karyawan”, Jurnal, Sekolah Tinggi Ilmu Ekonomi Widya Manggala, Semarang, 2012 . 